roots alongside; the difference in the weights merely represents the error of random sampling when numbers are small.

Prof. Bottomley is very scornful over my suggestion that the nutrient salts in the bacterial culture may have brought about an increase in yield, but if it is easy to represent their quantity as small to the verge of ridicule, exactly the same argument might be turned against the bacteria he added. No factor should be neglected to equalise the conditions of the controls and the treated plots. I can give Prof. Bottomley examples in which the nutrient salts accompanying a bacterial inoculation have not been negligible in their effects.

I put my questions to Prof. Bottomley because he does not seem to recognise how large an experimental error he must expect; the conclusions he reaches are of such importance as to demand a more serious body of evidence than the specially selected cases he has put before us.

A. D. HaLl.

The Rothamsted Experimental Station, December I3.

\section{Positions of Birds' Nests in Hedges.}

What has puzzled Lieut.-Colonel Walsh (Nature, December 16) may be referred to the law of protective devices on the part of birds, and I may say that his facts have been long familiar to other field naturalists and myself. I do not think that the direction north-south or east-west has anything to do with the selection of the nest site. If, at this season of the year, hedges are examined, even very careful "bird boys" and men will be astonished at a much larger number of nests than they observed in summer. If an explored hedge skirts on one side a public road, an "occupation" road, or right-of-way paths, it will be generally found that the nests are on the field side of the hedge, and, therefore, when looked for from the other side, much more difficult to discover than if they were placed on the road or pathway side. In cases where the hedge divides a field from a plantation, the nests are invariably on the plantation side. I knew that very well when I was a boy " nester," and was struck with it only a few days ago on examining a long stretch of hedge-fencing from a semi-public road near my home. However, there may be some esoteric law of bird-life in what Lieut.-Colonel Walsh says. Certainly his facts are most interesting.

Woodbine House, Bentham, Yorkshire, G. W. Murdoch. December I7.

\section{RADIUM AND CANCER.}

\section{T} $\mathrm{HE}$ Revue générale des Sciences of November 30 contains a lengthy and important article by Dr. Louis Wickham on the therapeutic action of radium on cancer, based upon observations made on 1200 patients suffering from tumours, half of which are stated to have been malignant. Dr. Wickham himself has demonstrated recently in London and in Belfast the nature of the results he has obtained, and full reports are available in the Proceedings of the Royal Society of Medicine and in the British Medical Journal. Therefore there is no need to reproduce the details of the article. The illustrations in the Revue générale des Sciences are even more startling than those which have appeared in the English journals cited. The appearances presented before and after treatment are such as will, almost surely, carry conviction to all laymen, whether healthy or suffering from cancer, that radium can cure the disease. But Dr. Wickham does not write in a corresponding spirit of optimism. Indeed, the only note of triumph is the phrase "It is delightful to think that the whole evolution of radiotherapy (the marvellous discovery of radium by $P$. Curie and Mme. Curie, the construction of perfected apparatus, therapeutical applications) is almost en- tirely French." No one may grudge this full measure of recognition to the advances made possible in Paris, on the biological action of radium, by collaboration between laboratories of physics, chemistry, and pathology. Not the least measure of praise is due to Dr. Wickham himself, both for his initiative and for his achievements.

Persons who possess an intimate knowledge of the clinical course and pathology of cancer will be less impressed by the pictures of cured cases than by what Dr. Wickham writes and what he omits to refer to. The evidence of diagnosis and of microscopical structure is imperfect. The diration of the period of benefit after treatment, as well as the ultimate fate of the patients, are the criteria by which the success of surgery is measured; but the evidence advanced in Paris falls short of good standards in both respects. Dr. Wickham lays no claim to successful treatment of secondary deposits; he says severe cases ought only to be treated when the surgeon can do nothing, and that it is too early yet to say if radium is the means which ought always to be employed, A warning is given of the necessity for caution in appraising the value of any new treatment, and, above all, of the necessity of avoiding the risk of depriving patients of other treatment which has proved itself superior, especially of surgery.

The results obtained in Paris have attracted the attention of the world. The hopes they have aroused have awakened yet greater expectations for the future, when larger quantities of radium shall be available, and the technique better mastered. Meantime, notwithstanding Dr. Wickham's caution, the writer considers a further note of warning is necessary. All that is claimed for radium is a beneficial action when applied directly to primary growths. Secondary growths inaccessible to direct surgical removal are inaccessible to radium in consequence of the restricted penetration of the rays. Whether or not means will be devised for attacking deep secondary depositsthe very site of which it may be impossible to determine -remains to be seen. The actual injection of emanation solution has met with no success. Nor is the evidence that radium has a marked elective action for cancer tissue so strong, at present, as to arouse any great hopes from more efficacious means of flooding the body with radio-activity. In short, radium does not appear to be nature's remedy for cancer, but an empirical remedy with the same shortcomings as all other such in the case of cancer, in that the local condition alone is attacked and the constitutional conditions are unassailable.

That the body can generate powers of its own, leading to constitutional changes which enable it to deal effectively with cancer, has been abundantly demonstrated by recent experiment. In given circumstances, Ioo per cent. of animals bearing transplanted tumours can cure themselves. The facts ascertained show that the natural forces of the body can cope both with secondary deposits and with primary growths. Though this process of natural cure is not, and may not speedily, be elucidated, still, it is not too sanguine an expectation to anticipate that ultimately it will be. The means for checking the ravages of cancer will be found, not by searching the surface of the earth for a vegetable remedy, nor the bowels of the earth for a mineral one, but by following the definite clue, that in the living body itself forces can be elicited which effectively combat the disease. Until that goal shall be attained, when surgery fails or is unavailable, relief may be sought, but cannot be guaranteed, by resorting to treatment with radium, the full possibilities of which are not yet developed, even in Paris.
E. F. B. 